\title{
CYCLIC TESTING SETUPS TO HIGHLIGHT THE IMPORTANCE OF HEATING AND OTHER REVERSIBLE PHENOMENA ON ASPHALT MIXTURES
}

\author{
Ramon Botella* (correspondence author), Félix E. Pérez-Jiménez*, Teresa López-Montero*, \\ Rodrigo Miró* \\ * Universitat Politècnica de Catalunya - BarcelonaTech \\ Jordi Girona 1-3, B1 215 \\ 08034 Barcelona, Spain
}

\begin{abstract}
This paper highlights the importance of the reversible phenomena in cyclic testing of asphalt mixtures. Several tests were designed to quantify the importance of these phenomena, focusing especially on heating due to viscous dissipation during cycling. Results showed that the decrease in stiffness observed during high frequency cyclic testing, and normally assumed by the conventional fatigue characterization procedures as damage, is in fact caused by reversible phenomena that are characteristic of visco-elasto-plastic materials under these conditions (heating, thixotropy, nonlinearity and healing). By obtaining the thermo-mechanical properties of the study mixture, the importance of heating within all reversible phenomena was studied.
\end{abstract}

Keywords: bituminous mixtures, asphalt, cyclic testing, fatigue, heating, thixotropy

\section{INTRODUCTION}

Cyclic testing is the most common method used to characterize fatigue behaviour of asphalt mixtures. The concepts inherited from the fatigue study of other materials, such as steel, have dominated the research lines that have tackled this problem. Therefore, most of the procedures developed to characterize fatigue behaviour of these materials are based on finding the number of cycles to failure for any loading using high-frequency cyclic tests, i.e., the fatigue law of the material.

This fatigue law, which is in fact an empirical relationship with no theoretical justification, is obtained in the laboratory from cyclic tests at constant strain or stress amplitude. Several tests at different strains or stress levels have to be performed in order to obtain the fatigue law. Those tests are known as time sweep tests. Classically, the evolution of the stiffness during these tests has been divided into three phases (Baaj, Di Benedetto, \& Chaverot, 2005). In phase I, a significant and sharp decrease of the dynamic modulus is observed. In phase II, the modulus decreases linearly and the slope of this decrease will depend on the applied loading amplitude. Finally, in phase III a sudden decrease of the modulus is observed. This phase is normally associated with the total failure of the material.

The majority of the methods that try to characterize fatigue behavior of asphalt mixtures are based on obtaining the number of cycles it takes in time sweep tests to reach phase III for every loading level. This approach assumes that all stiffness reduction observed during cyclic testing is associated with damage, and therefore is irreversible. However, several studies have proven that asphalt materials experience reversible changes in stiffness during cyclic testing (Di Benedetto, Nguyen, \& Sauzéat, 2011; Shan, Tan, Underwood, \& Kim, 2011). In 2012 PérezJiménez, et al., by using for the first time in asphalt materials an uniaxial alternative strain sweep test, showed that the greater part of the stiffness reduction observed in cyclic testing of these materials is recoverable only by reducing the strain amplitude applied (F. Pérez-Jiménez, 
Botella, \& Miró, 2012; F. E. Pérez-Jiménez, Botella, \& Miró, 2012). In the same study, it was shown that the stiffness stabilization value during cycling was independent of the previous loading history, giving more weight to the importance of the reversible phenomena.

For that reason, some researchers have focused on defining new failure criteria using other properties of the material other than stiffness, for instance dissipated energy and phase angle (Hou, Underwood, \& Kim, 2010; Mensching, Rahbar-Rastegar, Underwood, \& Daniel, 2016; Reese, 1997; Zhang, Sabouri, Guddati, \& Kim, 2013).

Since then, many researchers have focused on quantifying the importance of reversible phenomena (Canestrari, Virgili, Graziani, \& Stimilli, 2015; Isailović, Wistuba, \& Cannone Falchetto, 2017; Isailović, Wistuba, \& Falchetto, 2017; S. Mangiafico et al., 2015), showing that ignoring them in the fatigue characterization of mixtures can lead to erroneous conclusions, or inaccurate rankings regarding their final performance in the field. In 2015 Pérez-Jiménez et al. (Félix E. Pérez-Jiménez, Botella, Miró, \& Martínez, 2015), by comparing results from new time and strain sweep tests for asphalt binders (R. Botella, Pérez-Jiménez, \& Miró, 2012), concluded that the relationship between the complex modulus and dissipated energy density was linear during phase I and II, questioning the historical difference in behavior that has been assumed to exist between them. In addition, a linear relationship was found between the change of modulus with cycles and the change in energy with the modulus. This linear relationship was characteristic of each binder at a given temperature and frequency and could be used to predict the deterioration rate in a time sweep test, using a much shorter strain sweep test.

Among the irreversible phenomena that may affect cyclic testing of asphalt materials, the easiest to measure experimentally is heating. For that reason in 2017, Botella et al. (Ramon Botella et al., 2017) carried out a cyclic alternative strain sweep test on asphalt binder specimens with thermocouple probes inside. Results showed that the temperature increase during cycling was very important and could explain up to $90 \%$ of the stiffness reduction observed experimentally. In the same research project, the same test set up was applied to mixtures and a significant recovery in stiffness was observed, which would be consistent with heating. However, researchers were unable to measure temperature increases inside the mixture specimens. That was accomplished previously by other researchers (Lundström, Ekblad, \& Isacsson, 2004; S. Mangiafico et al., 2015) who were able to measure the change in temperature within an asphalt mixture sample by introducing rest periods. An increase in temperature during the load cycles followed by a decrease to the original temperature during the rest period was observed.

These results on binders were followed with the numerical modelling of these phenomena in binders and mixtures. Riahi et al. (Riahi, Allou, Botella, Dubois, et al., 2017; Riahi, Allou, Botella, Fakhari Tehrani, et al., 2017) modelled the increase in temperature in a mixture during cycling using a heterogeneous numerical model in which aggregates and mastic presented different thermal properties. Assuming the local predicted dissipated energy density as the heat source an estimation of the temperature increase of the specimen and the resultant complex modulus was obtained. The conclusion of this study was that the temperature change in the mixture could explain one third of the stiffness reduction.

Following this line of research, this paper presents the efforts to quantify the importance of the reversible phenomena that take place during cyclic testing of asphalt mixtures, focusing on heating due to viscous dissipation. Different kinds of tests with rest periods and alternative strain amplitude changes were designed in order to quantify the amount of heating, the 
importance of it and the total contribution of all reversible phenomena to the stiffness reduction during cyclic testing. Those results were compared with the thermal and thermomechanical properties of the mixtures in order to confirm the importance of heating.

\section{METHODOLOGY}

All the tests performed in this research project were conducted using the EBADE test configuration, Figure 1. The EBADE test is a uniaxial tension-compression strain sweep test that uses prismatic specimens with a notch in two of its flat faces. Its name stands for the Spanish words for strain sweep test. The prismatic specimens were carved from cylindrical samples compacted using the Marshall compactor at 75 blows per face. The steel pieces that attach the specimens to the test equipment were glued using an epoxy resin. The test is controlled by the strain that one of the two extensometers measures during the test. The reading of the other extensometer was used afterwards to corroborate that the specimen deformed more or less homogeneously during the test. More details about the EBADE test procedure and sample preparation can be found on (F. Pérez-Jiménez, Valdés, Miró, Botella, \& Campana, 2011).

Four different kinds of tests were carried out, conventional time sweep tests, time sweep tests with rest periods, incremental strain sweep tests with return to the lowest strain level, and frequency sweep tests. All of them were strain-controlled tests. The mixture employed was a BBTM8A (gap-graded), according to European standards, with a $5 \%$ binder content in mixture mass and a 50/70 pen bitumen. From now on, the study mixture will be referred to as a 50/70 mixture.

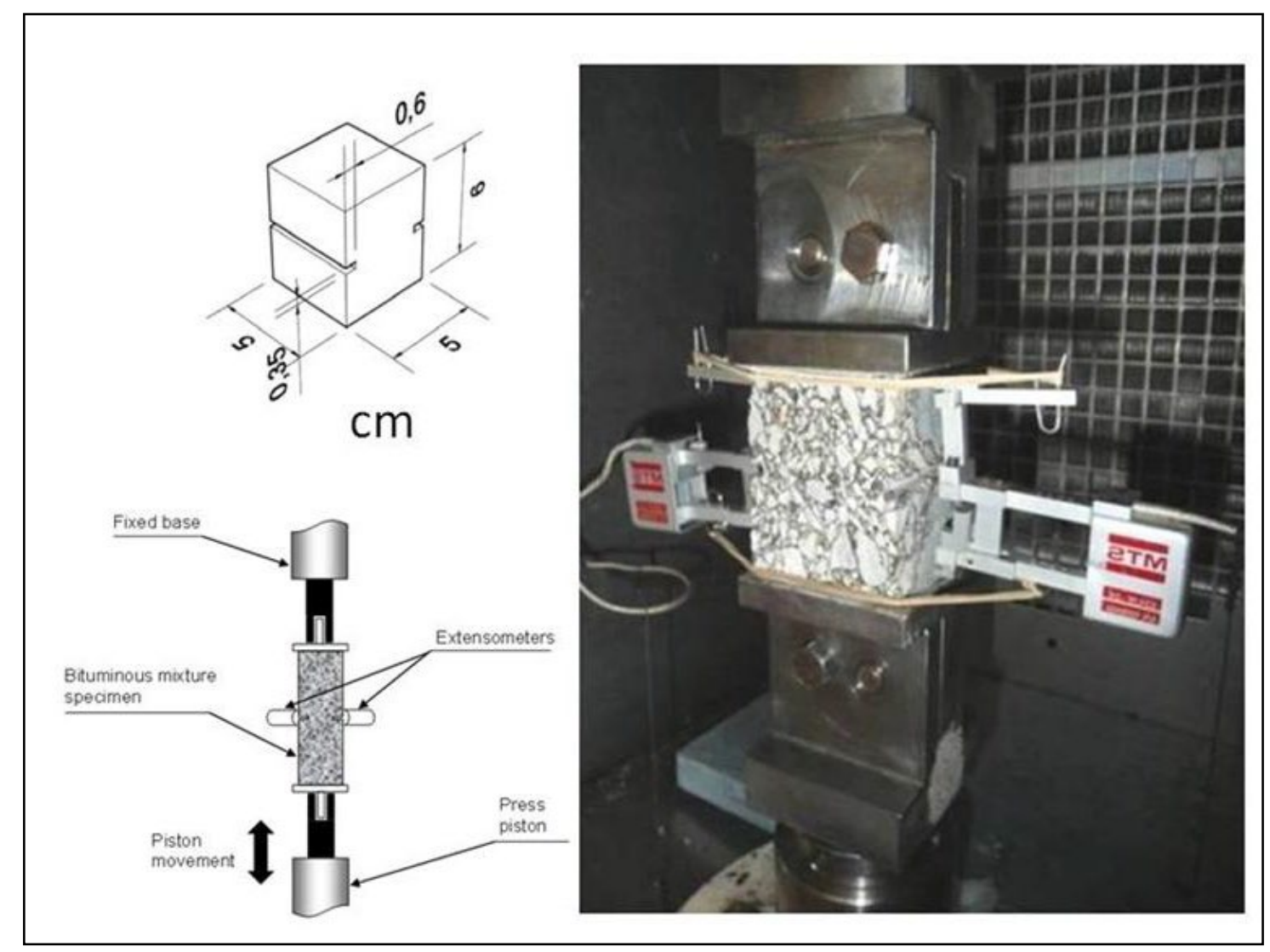

Figure 1. EBADE test setup. 


\section{Time sweep test with and without rest periods}

The time sweep tests were conducted to obtain the behaviour of the mixtures in the conditions at which the fatigue behaviour is studied in conventional procedures. Additionally, this test was used to measure the internal temperature of the mixture during cyclic testing. Several tests were conducted at $20^{\circ} \mathrm{C}$ and $10 \mathrm{~Hz}$ at two strain amplitudes ( 200 and 225 microstrains) on the 50/70 mixture. One of the specimens tested at 225 microstrains had a thermocouple probe embedded in the geometrical centre of the specimen. The probe was inserted by drilling a hole in one of faces without a notch, inserting the probe and sealing the hole using the same binder employed in the manufacturing of the mixture. The hole drilling may have caused some damage to the specimen, but the values recorded showed similar fluctuations than the expected from sample variation. The master curve was obtained using samples without holes, but since the complex modulus values were very similar, it was assumed that the influence of the hole on the stiffness of the specimen was less than the precision of the test itself. The strain was controlled using two on-specimen extensometers, figure 2 .

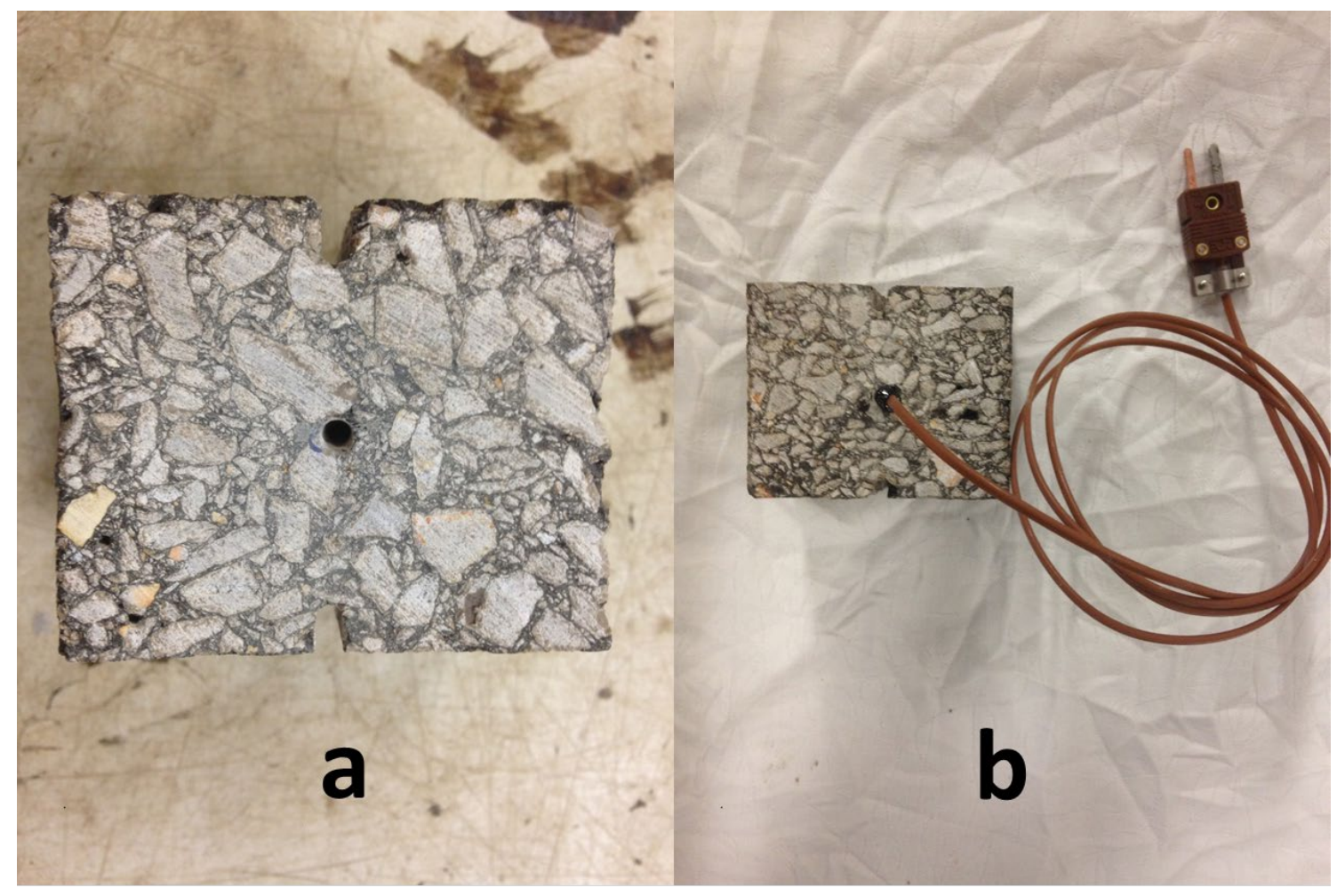

Figure 2. Details of the hole drilled in the specimens (a) and thermocouple inserted and sealed with the same $50 / 70$ binder (b).

Since the duration of the time sweep test with rest periods was very long, only two tests were conducted under those conditions. The first one at 200 microstrains with 10 minute rest periods every 200 cycles, and the second one at 225 microstrains with 5 minute rest periods every 200 cycles. The rest period's duration in the second test was reduced to half with respect to the first to reduce the hypothetical cooling down of the specimen and increase the differences in stiffness recovery between tests. These combinations of a short number of cycles with long rest periods were chosen by focusing on the hypothesis that heating in the mastic matrix due to viscous dissipation takes an important role in the stiffness of the mixture. Limiting the cycling blocks to 200 cycles, a hypothetical temperature build-up would be 
reduced and the long rest periods afterwards would allow the environmental chamber to reduce the internal temperature of the specimen before starting to cycle again. The test temperature and frequency were $20^{\circ} \mathrm{C}$ and $10 \mathrm{~Hz}$.

\section{Strain sweep tests}

The incremental strain sweep test consisted of modifying the strain amplitude every 5,000 cycles. The test started at 25 microstrains and the amplitude was increased after 5,000 cycles by 25 microstrains, i.e., the strain amplitude in the second block of 5,000 cycles was 50 microstrains. Once the second block was finished, the strain amplitude was reduced to 25 microstrains again for a duration of 5,000 cycles and then increased to 75 microstrains for another 5,000 cycles. This procedure was repeated up to a strain amplitude big enough to cause the total failure of the specimen. Summarizing, the strain is increased by 25 microstrains each time, but after each increase in strain, there is block of 5,000 cycles at 25 microstrains amplitude. Each one of the blocks will be referred to from now on as a "strain step" or simply a "step". There were two different kinds of strain steps: those in which the material experienced an increase in strain in relation to the previous step, and those in which the material experienced a decrease to the initial strain. The former will be referred to as "high strain steps" and the latter as "low strain steps". Figure 3 shows an example of the strain input signal applied.

These kinds of tests were conducted on the $50 / 70$ mixture at $20^{\circ} \mathrm{C}$ at $10 \mathrm{~Hz}$. The idea behind this set-up is that the high strain steps cause the stiffness of the material to reduce. However, without returning the material to the original testing conditions at which the stiffness was first measured, i.e., the low strain steps, it is impossible to tell if the reduction of the stiffness is definitive (damage) or reversible (heating, thixotropy, non-linearity, etc.).

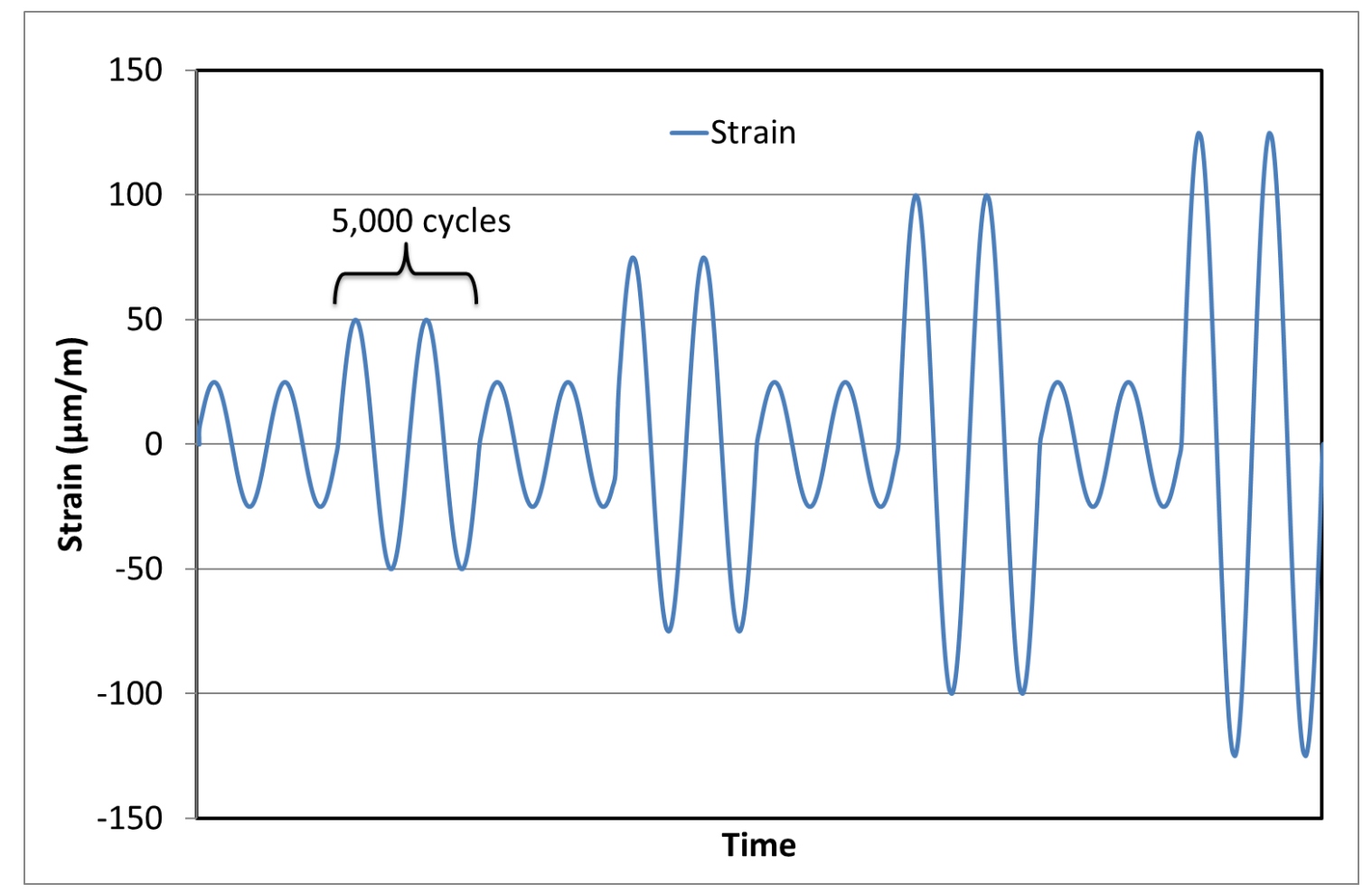

Figure 3. Example of a strain input signal in an incremental strain sweep test with return to the lowest strain level. 


\section{Frequency sweep test}

Using the EBADE test set-up, frequency sweeps were carried out at different temperatures to obtain the thermal susceptibility of the $50 / 70$ mixture. The temperatures chosen were $-5,+5$ and $+20^{\circ} \mathrm{C}$, the frequency sweep went from $0.1 \mathrm{~Hz}$ to $10 \mathrm{~Hz}$ and the strain amplitude was 50 microstrains. This strain amplitude is half of what normally is assumed to be the linear viscoelastic (LVE) limit of bituminous mixtures, i.e., 100 microstrains (Airey \& Rahimzadeh, 2004; Olard, Di Benedetto, Eckmann, \& Triquigneaux, 2003). Studies that are more recent indicate that this limit changes with the temperature and frequency applied for the same material, and it can be as low as 10 microstrains at very low frequencies or very high temperatures (Nguyen, Di Benedetto, \& Sauzéat, 2014). Since the bulk of the tests performed in this research project were conducted at $10 \mathrm{~Hz}$, assuming 50 microstrains to be within the LVE limit seems reasonable. The construction of the master curves was made using the Williams-Landel-Ferry equation to fit the shift factors (Williams, Landel, \& Ferry, 1955) and the 2S2P1D model to obtain the dependency of the complex modulus norm on the frequency and temperature (Salvatore Mangiafico et al., 2016). The 2S2P1D stands for 2 springs, 2 parabolic elements and 1 dashpot. This model assumes that a system such as one spring $\left(E_{0}\right)$ in line with two parabolic elements $(h, k)$ and one dashpot $(\eta)$ all of them parallel to another spring $\left(E_{00}\right)$ can represent the linear-viscoelastic behaviour of the asphalt mixture at different temperatures and frequencies. By solving this system it is possible to obtain and analytical expression for the complex modulus for each temperature and frequency, i.e., equation 1.

$$
E^{*}(\omega)=E_{00}+\frac{E_{0}-E_{00}}{1+\delta\left(i \omega a_{T} \tau_{0}\right)^{-k}+\left(i \omega a_{T} \tau_{0}\right)^{-h}+\left(i \omega \beta a_{T} \tau_{0}\right)^{-1}},
$$

where $E_{0}$ and $E_{00}$ are the maximum and minimum modulus values the material can obtain, respectively, $\mathrm{k}$ and $\mathrm{h}$ are the dimensionless parameters associated with each of the parabolic elements, $\delta$ is a dimensionless parameters, $\beta$ is a dimensionless parameters related with viscosity, $a_{T}$ is the shift factor at the given temperature and $\tau_{0}$ is the characteristic time at the reference temperature chosen.

\section{Cooling curve}

Using the same environmental chamber in which all the tests were conducted, the temperature at the geometrical centre of one EBADE test specimen was monitored while cooling down from $28^{\circ} \mathrm{C}$ to $5^{\circ} \mathrm{C}$. This way, a cooling curve was obtained that would later help estimate the time it takes for the environmental chamber to change the temperature in the geometrical centre of the specimen.

\section{RESULTS}

This section is divided into three subsections. In the first subsection, the temperature measurements in the time sweep tests without rest periods are compared with the temperature susceptibility results obtained for the 50/70 mixture. In the second subsection, the effect of the rest periods is analysed by comparing the results of the time sweep tests with and without rest periods obtained for the 50/70 mixture. In the third subsection, the results obtained in the incremental strain sweep tests with return to the lowest strain level are analysed for the $50 / 70$ at $20^{\circ} \mathrm{C}$ and $10 \mathrm{~Hz}$.

\section{Temperature susceptibility and heating}


Figure 4 shows the evolution of the norm of complex modulus and the temperature inside the specimen of the $50 / 70$ mixture during a time sweep test at $20^{\circ} \mathrm{C}$ and $10 \mathrm{~Hz}$ at a strain amplitude of 225 microstrains.

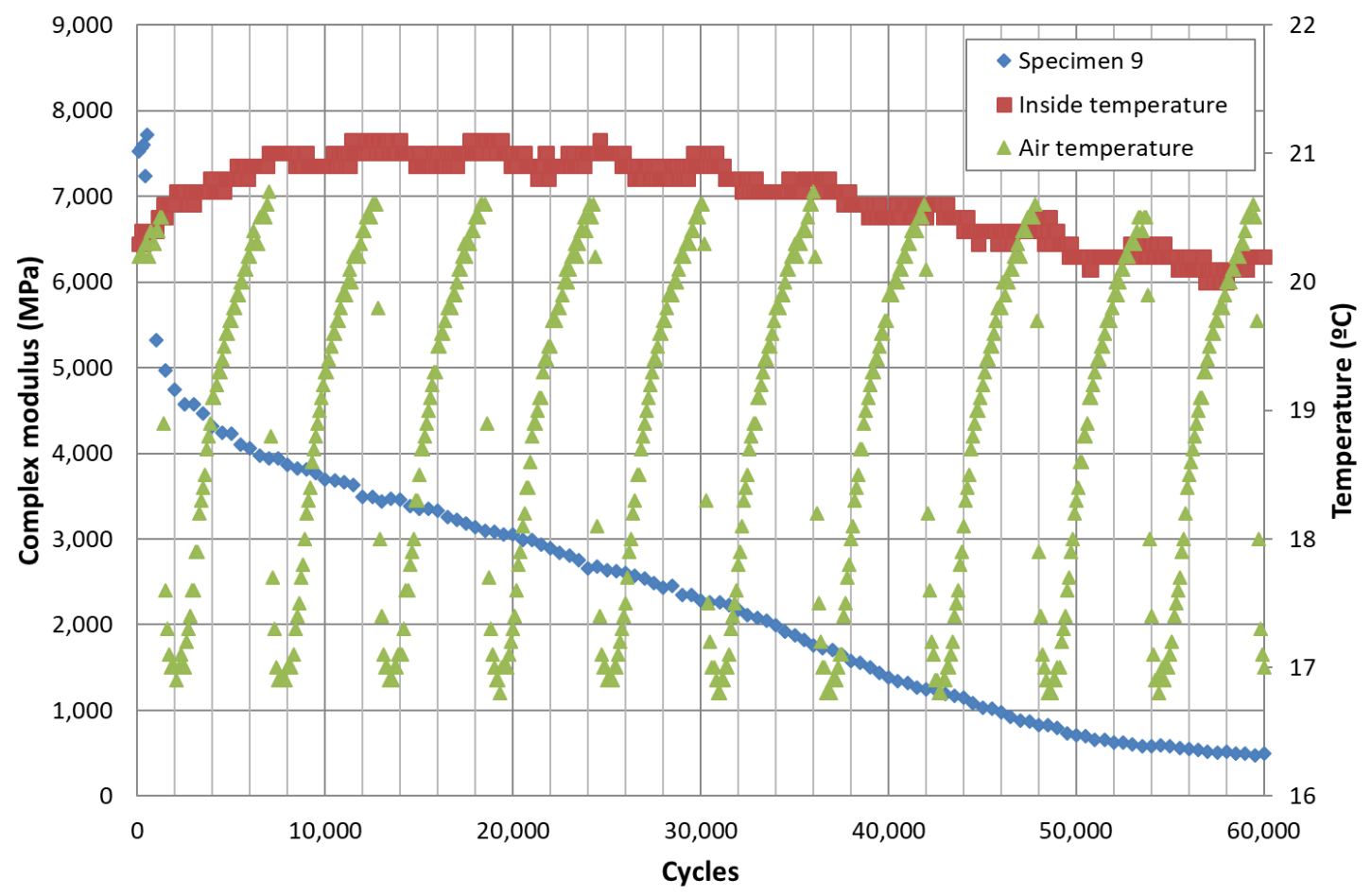

Figure 4. Norm of the complex modulus and internal temperature evolution during a time sweep test at $20^{\circ} \mathrm{C}, 10 \mathrm{~Hz}$ and 225 microstrains.

Before starting the time sweep test at 225 microstrains, 500 cycles are applied to the specimen at the lowest strain level possible for the test equipment, i.e., 25 microstrains. This initial conditioning is used to obtain a reliable complex modulus and phase angle measurements for the comparison between different replicates tested at different strain levels. The cluster of blue dots between 7,000 and $8,000 \mathrm{MPa}(7,530 \mathrm{MPa}$ on average) represents the data obtained during this initial conditioning. The internal temperature remained constant at $20.4^{\circ} \mathrm{C}$ during this initial conditioning. It is worth noting that the first value recorded at 225 microstrains for cycle 1,000, 500 cycles after starting the test with the target strain level, was $30 \%$ lower than the modulus recorded at 25 microstrains. This may be associated with non-linearity, as well as heating and thixotropy of the material.

During the first 10,000 cycles the internal temperature experienced a relatively quick increase that stopped at $21.1^{\circ} \mathrm{C}$, and then fluctuated between this value and $20.8^{\circ} \mathrm{C}$ until cycle 32,500 . By this time, the complex modulus had experienced a decrease of $72 \%$ with respect to the value at 25 microstrains and of $40 \%$ of the modulus value at 500 cycles at 225 microstrains. Therefore, by the conventional failure criterion that defines failure as the number of cycles to reduce the norm of the complex modulus to $50 \%$ the value of $100^{\text {th }}$ cycle, the specimen had nearly failed.

The temperature increase recorded was very low, less than $1^{\circ} \mathrm{C}$. The master curve obtained for this mixture using the same loading configuration did not predict the decrease of the complex modulus observed, figure 5 . The master curve was constructed following the procedure detailed below: 
- The complex modulus isotherms curves were plotted for the three frequencies.

- $5^{\circ} \mathrm{C}$ was chosen as reference temperature, values for $\mathrm{a}_{\mathrm{T}}$ at $-5^{\circ} \mathrm{C}$ and $20^{\circ} \mathrm{C}$ were estimated to sketch a first approximation to a continuous master curve.

- The previous $a_{\mathrm{T}}$ values were fitted to the Williams-Landel-Ferris expression (Williams et al., 1955) using the least squares method, obtaining $C_{1}$ and $C_{2}$ coefficients. New values of $a_{T}$ were computed using the WLF and the obtained coefficients.

- Then, the 2S2P1D expression (Olard \& Di Benedetto, 2003) was fitted to the data using the least squares method again.

The average relative error between the experimental value of the norm of the complex modulus and the values provided by the 2S2P1D fit were $5.3 \%$ with a standard deviation of $6.5 \%$. Nearly all the relative errors were below $3.5 \%$ with the exception of the values corresponding to $0.1 \mathrm{~Hz}$ and $1 \mathrm{~Hz}$ at $20^{\circ} \mathrm{C}$, which showed relative errors of $19 \%$ and $15 \%$ respectively. More details about the 2S2P1D model, how to use it construct a master curve for asphalt mixture and reference values of the different parameters for different mixtures can be found on (Salvatore Mangiafico et al., 2016).

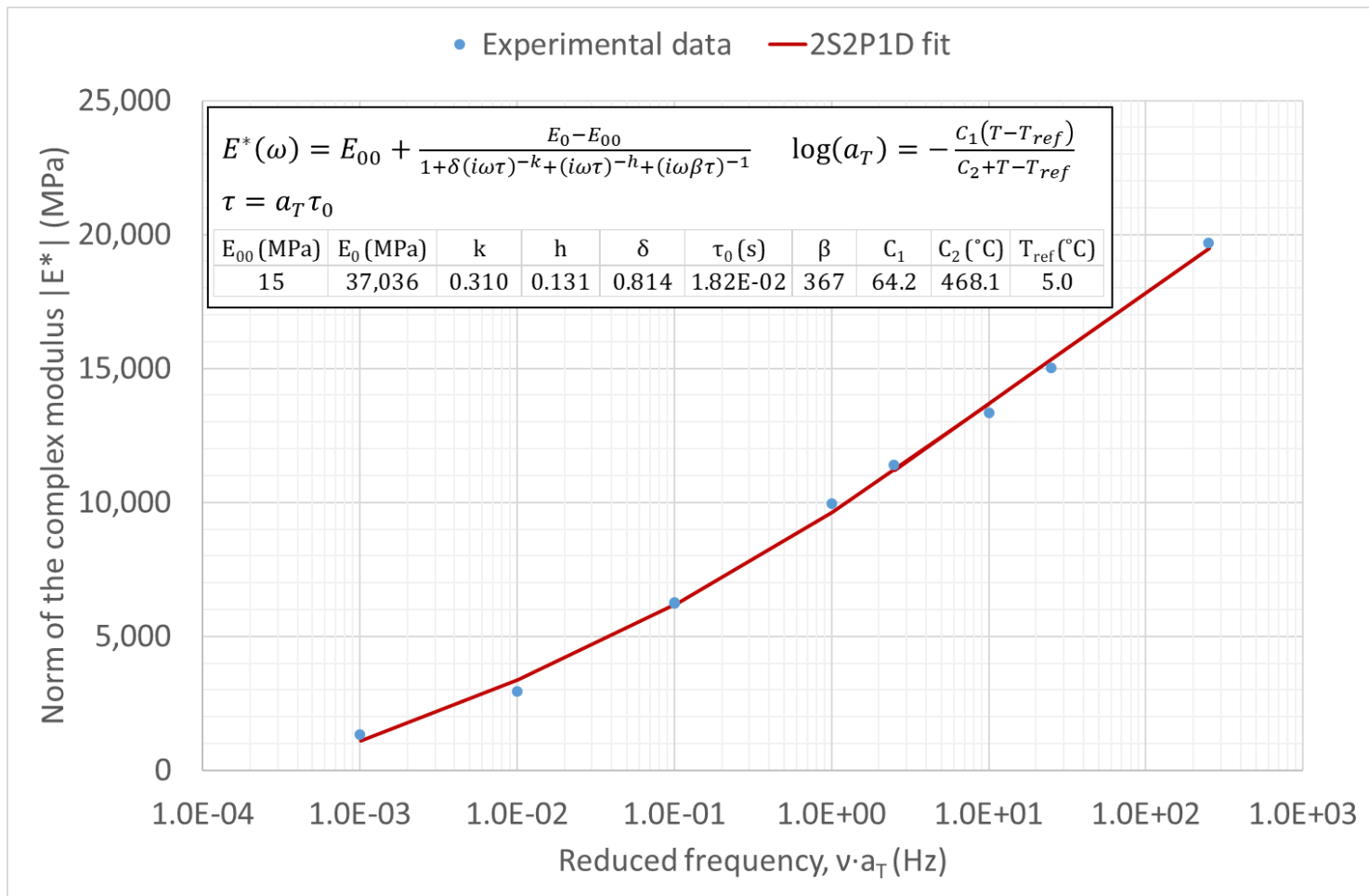

Figure 5. Master curve obtained for the 50/70 mixture using the EBADE tests loading configuration.

By recalibrating the master curve results for the sample variability between specimen 9 and those used to obtain the thermal susceptibility of the mixture, the expected temperature for the modulus values recorded during the initial 12,000 cycles of the test were obtained, figure 6. The recalibration process consisted of correcting the master curve by changing the value of the norm of the complex modulus at $20^{\circ} \mathrm{C}$ and $10 \mathrm{~Hz}$ for the initial value obtained in the test at 25 microstrains for the new specimen. In other words, the original master curve was shifted to fit the complex modulus value obtained in the initial/low-strain phase of the test (25 microstrains, $20^{\circ} \mathrm{C}$ and $10 \mathrm{~Hz}$ ). 




Figure 6. Expected average specimen temperature according to the master curve for the complex modulus values recorded.

It can been seen that by cycle 500 , the modulus recorded would correspond to a temperature of $27^{\circ} \mathrm{C}$, while the measurements indicate temperatures between 20.3 and $20.4^{\circ} \mathrm{C}$ at this point. However, the difference between the modulus at cycle 500 at high strain amplitude and the modulus at low strain amplitude may be strongly affected by non-linearity.

By cycle 11,000 the expected temperature is over $33^{\circ} \mathrm{C}$ while the measurements reach a maximum value of $21.1^{\circ} \mathrm{C}$. It should be noted that the measurement of the temperature in the geometrical centre of the specimen is not a reliable method to obtain the average temperature of the specimen nor for measuring the temperature of the mastic matrix that holds the specimen together. The reason for that is explained in the next paragraph.

The thermocouple probe was inserted in a hole carved in the specimen, figure 2 . As the great part of the mixture in volume is aggregate, binder takes up less than $12 \%$ of the volume with respect to the aggregates, there is a high probability that the thermocouple probe is placed on or surrounded by aggregates. Aggregates are mostly elastic so they can only heat by friction with other aggregates, or by contact with the hypothetically heated asphalt, but the relative movements between them should be very small. In addition, it is practically impossible to carve a hole in the specimen that assures that the tip of the thermocouple will fall on the mastic matrix, which is the material that can experience heating by viscous dissipation (Ramon Botella et al., 2017).

\section{Time sweep tests with and without rest periods}

The time sweep tests with and without rest periods were carried out at $20^{\circ} \mathrm{C}$ and $10 \mathrm{~Hz}$ and two different strain amplitudes, i.e., 200 and 225 microstrains. The rest periods introduced in the 200 microstrains test consisted of 10 minutes every 200 cycles, while in the 225 
microstrains test they were 5 minutes every 200 cycles. The evolution of the norm of the complex modulus during the tests with and without rest periods is shown in figures 7-10.

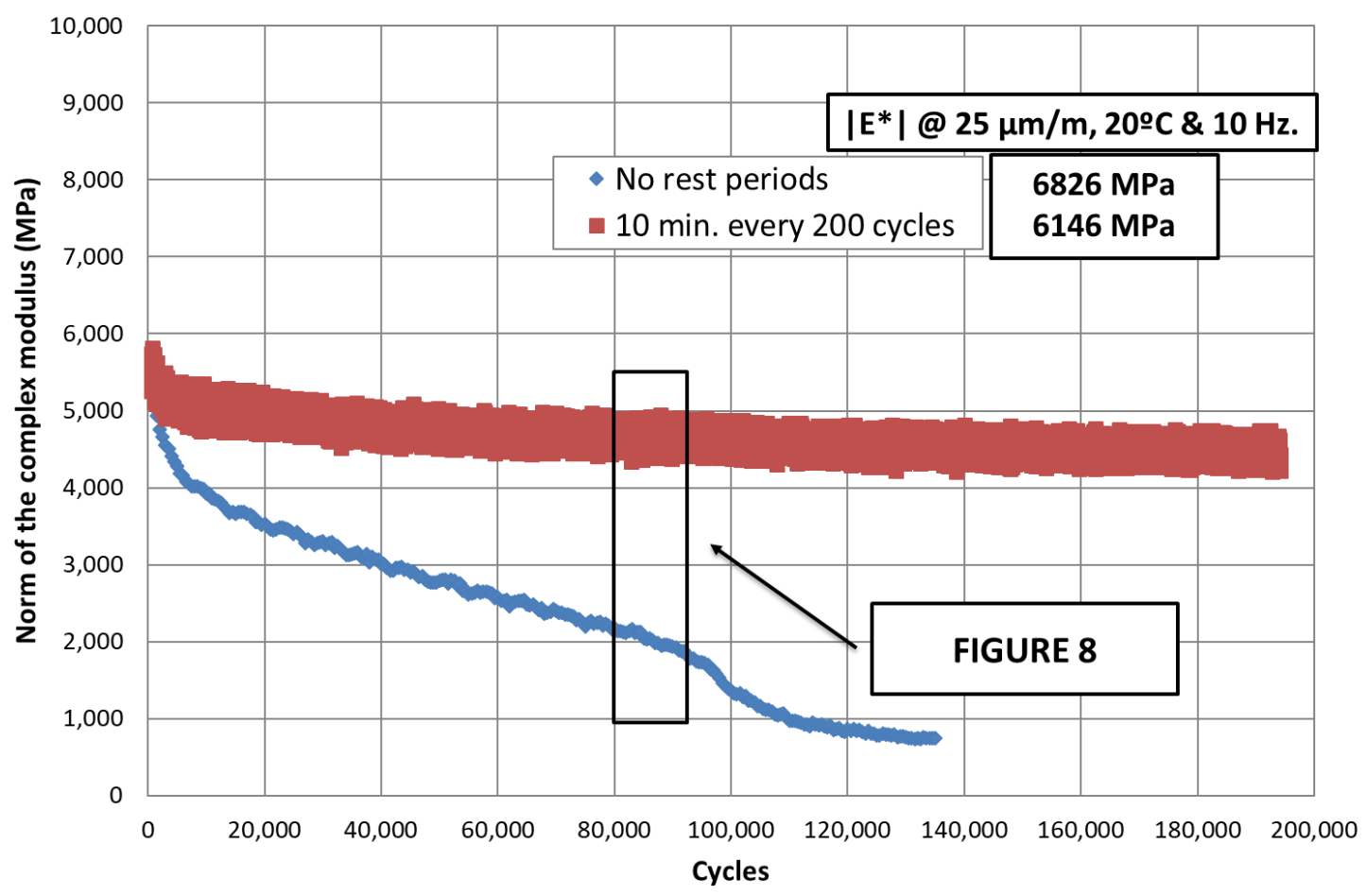

Figure 7. Time sweep tests at 200 microstrains, $20^{\circ} \mathrm{C}$ and $10 \mathrm{~Hz}$ with and without rest periods.



Figure 8. Enlargement of figure 7 between 80,000 and 90,000 cycles, for more detail. 


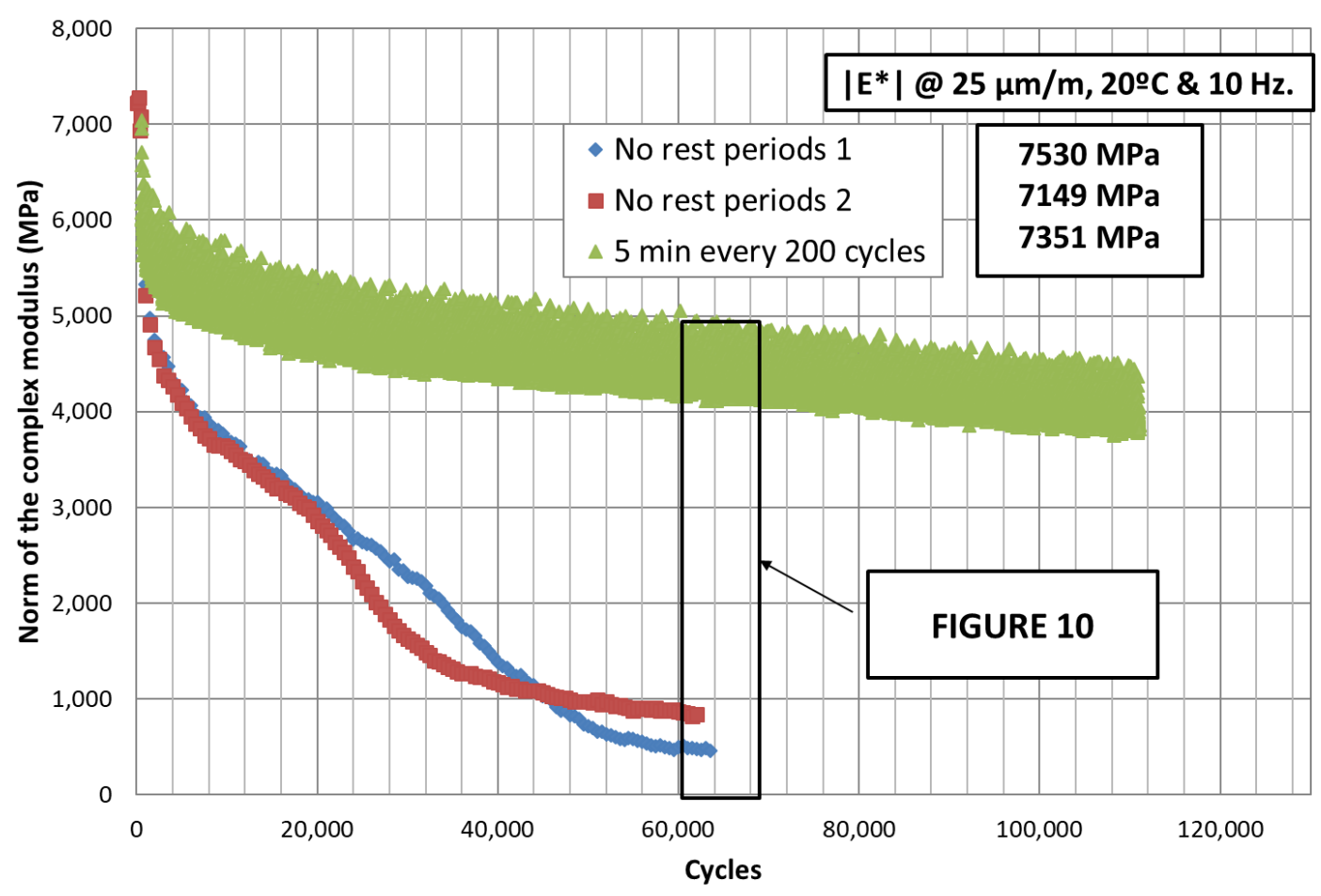

Figure 9. Time sweep tests at 225 microstrains, $20^{\circ} \mathrm{C}$ and $10 \mathrm{~Hz}$ with and without rest periods.

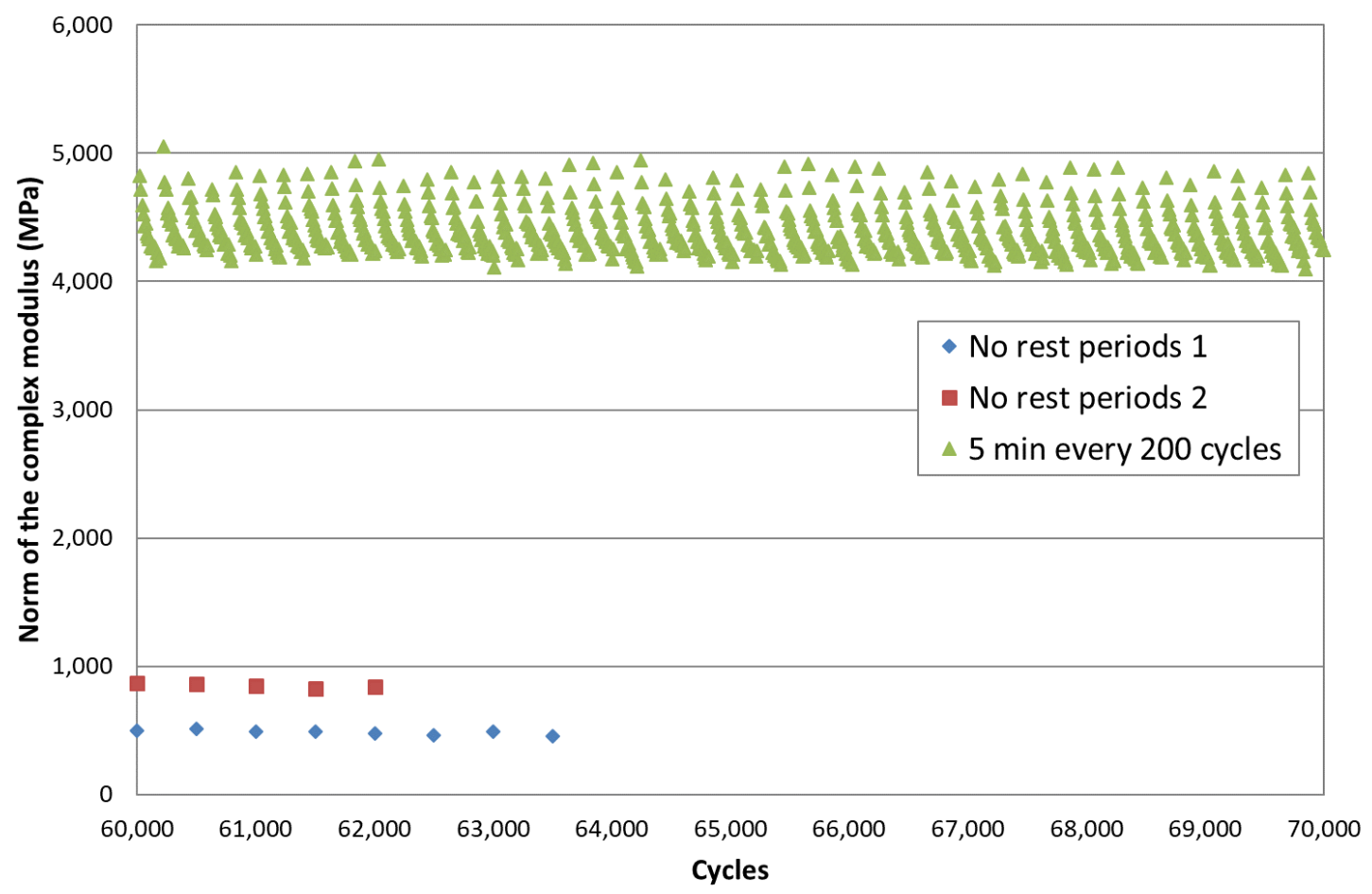

Figure 10. Enlargement of figure 9 between 60,000 and 70,000 cycles, for more detail.

The differences in the evolution of the complex modulus during the time sweep tests with and without rest periods were obvious, as figures 7-10 show. The complex modulus measured in previous testing at low strain amplitude, i.e. 25 microstrains, for each specimen is stated in the graph for comparison purposes. 
The time sweep tests at 200 and 225 microstrains caused failure of the specimens approximately at 100,000 and 30,000 cycles, respectively, i.e., transition between phase II and phase III of the stiffness-cycles curve. However, failure was not reached for any of the tests performed with rest periods. What is more, the decrease in stiffness observed was much lower. It is interesting to observe the complex modulus behaviour within each block of 200 cycles between rest periods. The difference between the modulus at the beginning and end of each 200 cycles block is around $350 \mathrm{MPa}$ for the test at 200 microstrains and around $700 \mathrm{MPa}$ for the test at 225 microstrains. In between, the shape of the complex modulus vs. cycles curve could be very accurately fitted by an exponential decay expression, which typically represents the reversible stiffness phenomena. The heating of the mastic matrix of the specimen due to viscous dissipation during cycling followed by a cooling down process during resting would explain this kind of behaviour. The thixotropy and the non-linear effects associated with the high level of strain applied could play an important part in this recovery as well. Self-healing of cracks can also produce such an effect, but previous studies have demonstrated that its effects are reduced at $20^{\circ} \mathrm{C}$ and without crack-closing pressure (Ayar, Moreno-Navarro, Sol-Sánchez, \& Rubio-Gámez, 2018).

\section{Heating hypothesis}

In this subsection, the results of the time sweep test with and without rest periods are analysed assuming the hypothesis that the only mechanism that reduces the stiffness is the heating of the mastic matrix of the mixture due to the viscous dissipation.

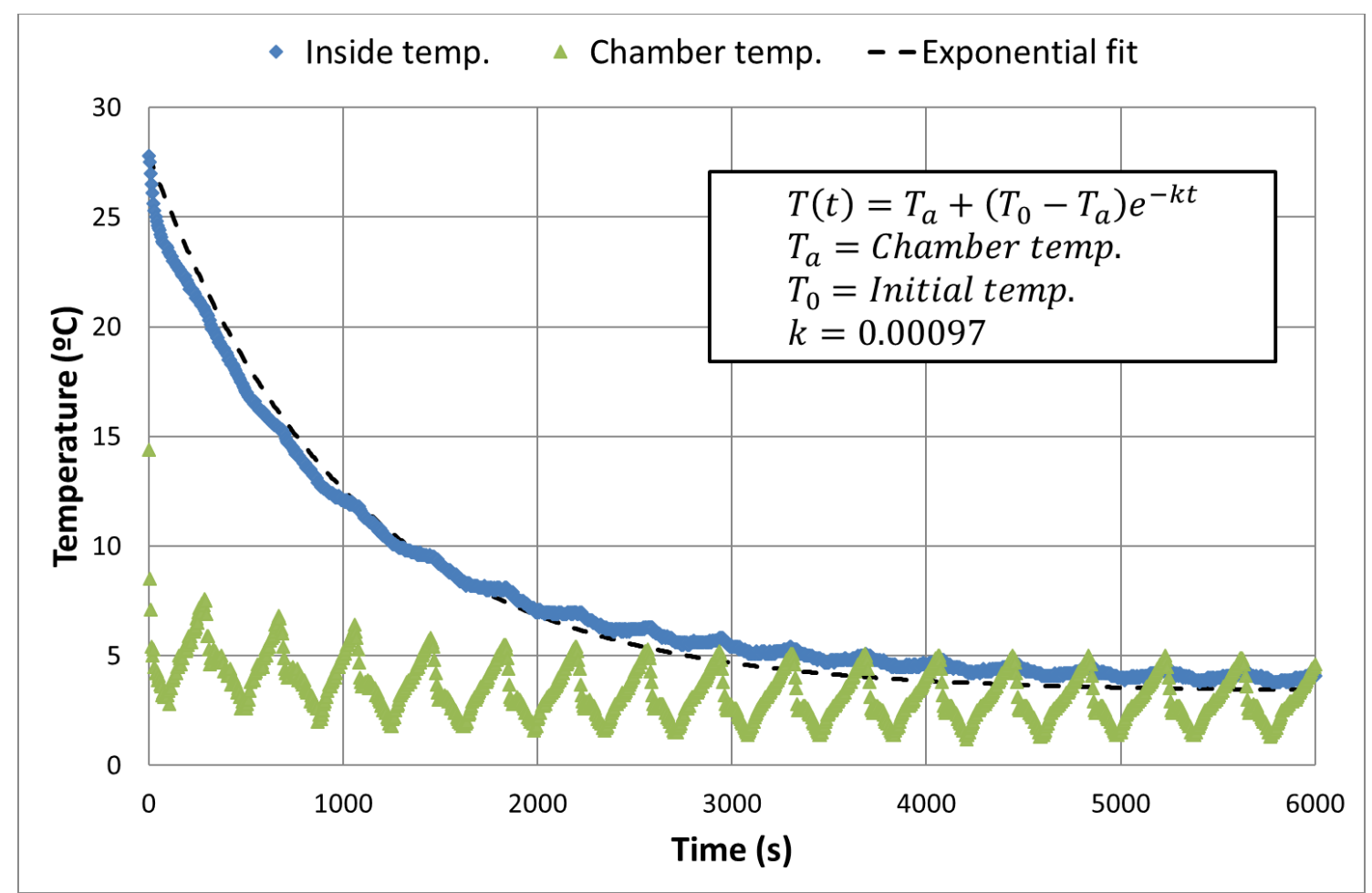

Figure 11. Cooling curve for an EBADE test specimen of the $50 / 70$ mixture in the environmental chamber.

The cooling curve shown in figure 11 was used to estimate how long it would take the environmental chamber to cool down the geometrical centre of the specimen from a hypothetical temperature increase. The first thing to notice is that, given the hypothetical temperature increases given by the master curve if all stiffness reduction is associated with 
heating, neither 5 nor 10 minutes were enough to cool down the specimen to the initial test temperature. Therefore, each cycling block would start with the specimen at a higher temperature, and that would explain the slow but constant decrease in stiffness observed in figures 7-10.

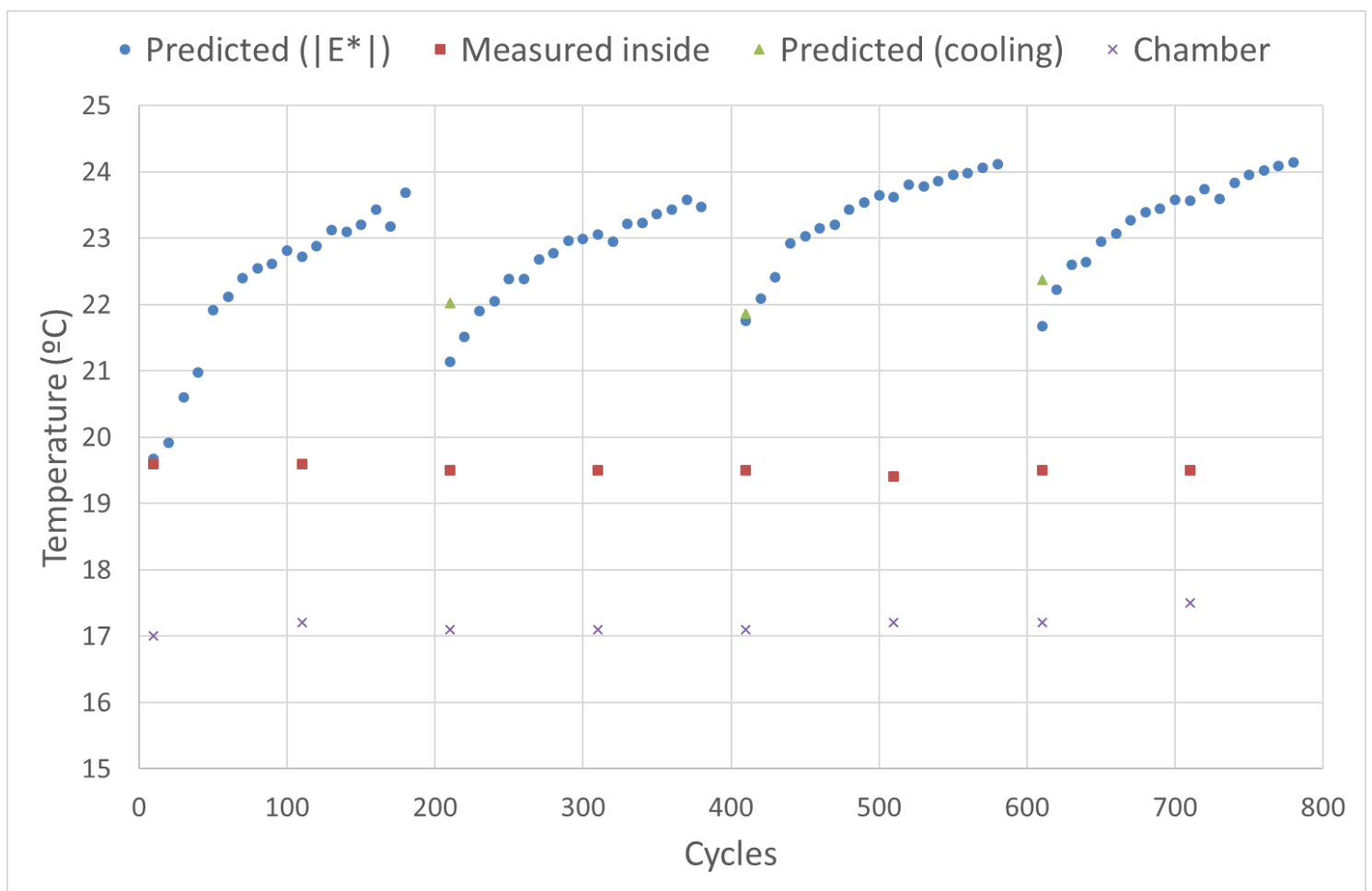

Figure 12. Measured and predicted temperatures for the initial part of the time sweep test at 225 microstrains and 5 minute long rest periods.

Figure 12 shows different values of temperature that are explained below:

- Circle marker: temperature obtained by plugging the experimentally measured norm of the complex modulus into the $2 \mathrm{~S} 2 \mathrm{P} 1 \mathrm{D}$ equation.

- Square marker: temperature registered in the geometrical centre of the specimen by the thermocouple.

- Triangle marker: temperature predicted by the cooling down equation from figure 11 , after the 5-minute rest period, taking as initial temperature the final temperature obtained in the previous cycling block from the 2S2P1D equation.

- Cross marker: air temperature inside the environmental chamber.

Given the air temperature of the environmental chamber and the duration of the rest period, the temperature predicted by the cooling down curve is quite consistent with the temperature associated with the modulus values recorded after the rest period. Assuming the specimen is heated during cycling, the 5 minute rest period is not enough to cool down the specimen to the target test temperature before starting to cycle again. However, the temperature captured with the thermocouple probe in the geometrical centre of the specimen remained constant through the whole test. 


\section{Strain sweep tests}

The strain sweep tests with return to the lowest strain level were conducted at $20^{\circ} \mathrm{C}$ and $10 \mathrm{~Hz}$ on a 50/70 mixture specimen. A maximum strain level was fixed for each of the two types of tests conducted, i.e., 150 and 275 microstrains. Once the maximum strain was reached and sustained for 5,000 cycles, the strain amplitude was reduced to 25 microstrains indefinitely. The tests were stopped after confirming that the complex modulus values were stabilized. The objective of prolonging the cycling at low strain after reaching a relatively high strain amplitude was to let the specimen cool down to the initial test temperature from a hypothetical heating during cycling, figure 13 . The 25 microstrains amplitude is assumed to be too low to produce any heating since it is associated with a very low value of dissipated energy density.

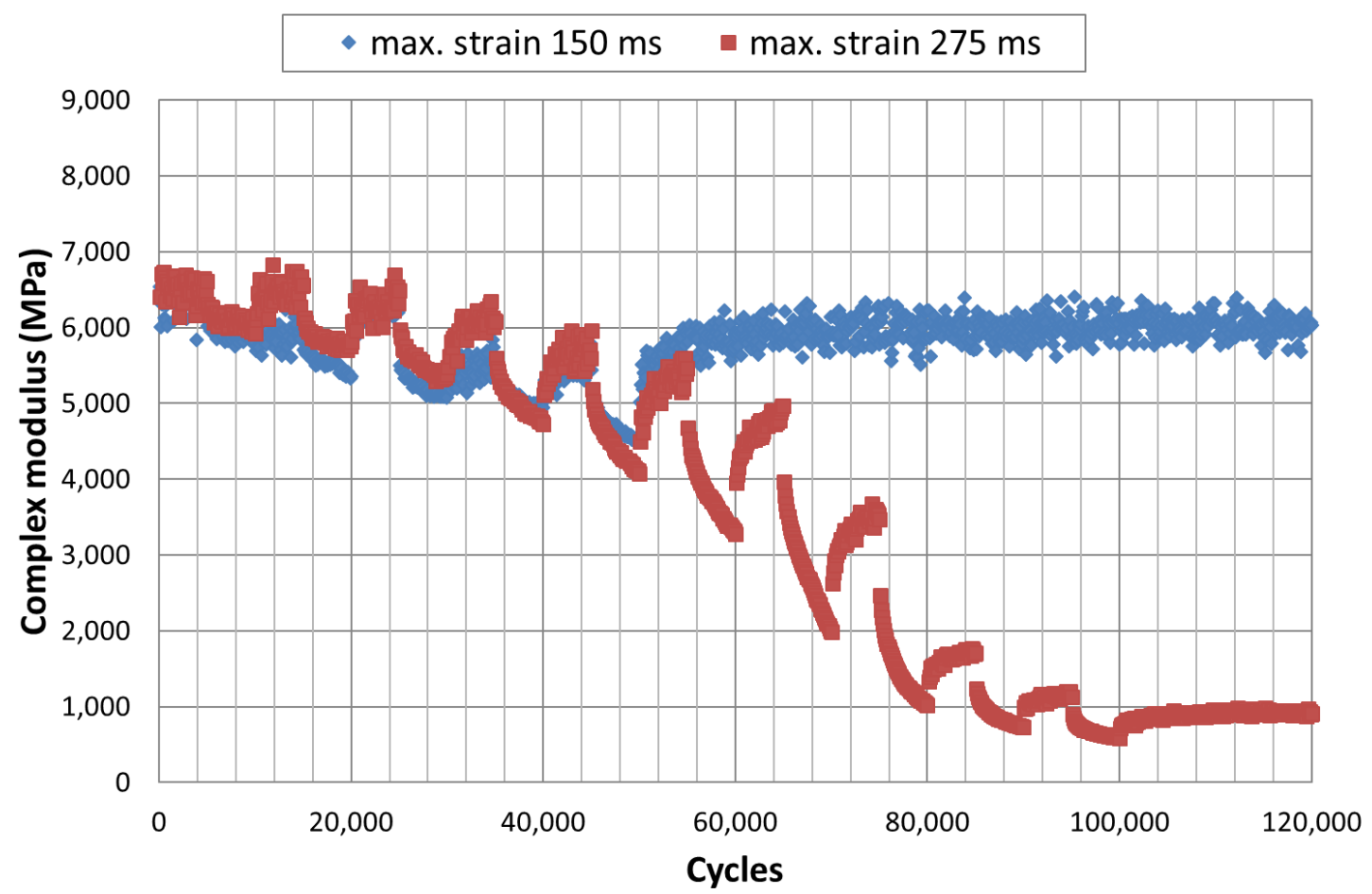

Figure 13. Strain sweep tests at $20^{\circ} \mathrm{C}$ and $10 \mathrm{~Hz}$ on the $50 / 70$ mixture with limited maximum strain.

Figure 13 shows how both replicates show the same behaviour up to 50,000 cycles. The alternation between high and low strain levels is clearly seen in the plot, i.e. at high strains the complex modulus drops following an exponential decay type of curve, while at low strains the complex modulus increases following a logarithmic rise type of curve. This kind of behaviour is characteristic of temperature changes (Ramon Botella et al., 2017), as it is of crack opening and crack sealing associated with the healing capabilities of the binder. However, at $20^{\circ} \mathrm{C}$ and $10 \mathrm{~Hz}$ the flow ability of the binder may be reduced significantly, making it quite difficult to restick previously opened cracks. It is quite interesting to observe how the change in the strain amplitude pattern after 50,000 produced two different results. The specimen that did not experience strains higher than 150 microstrains recovered the initial stiffness almost completely (during the first 5,000 cycles the average modulus was 6,313 $\mathrm{MPa}$ and from cycle 80,000 to 700,000 the average value was $5,992 \mathrm{MPa}$ ). Using the complex modulus values at different stages of the test the importance of reversible phenomena and damage can be 
quantified. For instance, at $150 \mathrm{~ms}$ the lowest complex modulus values was $4,510 \mathrm{MPa}$, but the specimen was able to recover up to 5,992 $\mathrm{MPa}$, knowing that the initial value was $6,313 \mathrm{MPa}$, out of 1,803 MPa of stiffness reduction, $321 \mathrm{MPa}$ were unrecoverable (probably caused by damage) and 1,482 MPa were recovered (associated with reversible phenomena).

On the other hand, the specimen that suffered strain amplitudes as high as $\mathbf{2 2 5}$ microstrains did not recover the stiffness at all. In fact, between 65,000 and 70,000 cycles (200 microstrains) the modulus drop was much higher than in previous steps and its shape was closer to a linear drop than an exponential decay.

\section{CONCLUSIONS}

The main objective of this research project was to quantify the importance of the reversible phenomena that take place during cyclic testing of asphalt mixtures, with special focus on the importance of the heating of the material due to viscous dissipation. Heating during cycling proved to be very important in asphalt binders (Ramon Botella et al., 2017; Lundström et al., 2004; Félix E. Pérez-Jiménez et al., 2015), therefore a certain amount of heating should be expected in asphalt mixtures.

Measurements of the core temperature of specimens during time sweep tests using the EBADE configuration showed a much reduced increase in temperature. The temperatures recorded could not explain the complex modulus reduction.

However, results show the great importance of rest periods and the capabilities of the mixture regarding stiffness recovery. The comparison between time sweep tests with and without rest periods demonstrated that these types of tests are not adequate for simulating the behaviour of the mixture in the field, in which loads are prominently discontinuous. Clearly, there is a build-up phenomenon, which can be a combination of heating, thixotropy and nonlinearity that reduces the stiffness very quickly in cyclic testing, but is completely reversible if the strain applied stays below a certain limit. For the mixture studied at $20^{\circ} \mathrm{C}$ and $10 \mathrm{~Hz}$, this limit was over 150 microstrains and below 275 microstrains, figure 13 .

The strain limit below which the mixture only experiences reversible phenomena, at a given temperature and frequency, should be used to characterize the so-called fatigue behaviour of the mixture, and replace the cycles to failure approach.

Given the results of this paper, it seems highly probable that heating takes a major role in the stiffness reduction of asphalt mixtures during cycling. However, this temperature accumulation is highly unlikely in the field. Asphalt mixtures are subjected to a non-continuous loading process in the pavement where there is a period between the passing of a heavy traffic load and the next. Besides, it should be added that it might take an even longer period for a truck to pass twice through the same point. For that reason, it is important to acknowledge this behaviour and consider it when choosing an asphalt mixture for the pavement.

\section{ACKNOWLEDGEMENTS}

Part of the research presented on this paper belongs to the project BIA2015-67494-P that has been cofounded by the Spanish Ministry of Economy, Industry and Competitiveness, inside the National Program for Fostering Excellence in Scientific and Technical Research, National Subprogram of Knowledge Generation, 2015 call, in the framework of the Spanish National Plan for Scientific and Technical Research and Innovation 2013-2016, and by the European 
Union, through the European Regional Development Fund, with the main objective of Promoting technological development, innovation and quality research.

\section{REFERENCES}

Airey, G. D., \& Rahimzadeh, B. (2004). Combined bituminous binder and mixture linear rheological properties. Construction and Building Materials. https://doi.org/10.1016/j.conbuildmat.2004.04.008

Ayar, P., Moreno-Navarro, F., Sol-Sánchez, M., \& Rubio-Gámez, M. C. (2018). Exploring the recovery of fatigue damage in bituminous mixtures: the role of rest periods. Materials and Structures/Materiaux et Constructions. https://doi.org/10.1617/s11527-018-1146-7

Baaj, H., Di Benedetto, H., \& Chaverot, P. (2005). Effect of binder characteristics on fatigue of asphalt pavement using an intrinsic damage approach. Road Materials and Pavement Design, 6(2), 147-174. https://doi.org/10.1080/14680629.2005.9690003

Botella, R., Pérez-Jiménez, F. E., \& Miró, R. (2012). Application of a strain sweep test to assess fatigue behavior of asphalt binders. Construction and Building Materials, 36, 906-912. https://doi.org/10.1016/j.conbuildmat.2012.06.059

Botella, Ramon, Pérez-Jiménez, F. E., Riahi, E., López-Montero, T., Miró, R., \& Martínez, A. H. (2017). Self-heating and other reversible phenomena in cyclic testing of bituminous materials. Construction and Building Materials, 156, 809-818. https://doi.org/10.1016/j.conbuildmat.2017.09.036

Canestrari, F., Virgili, A., Graziani, A., \& Stimilli, A. (2015). Modeling and assessment of selfhealing and thixotropy properties for modified binders. International Journal of Fatigue, 70, 351-360. https://doi.org/10.1016/j.ijfatigue.2014.08.004

Di Benedetto, H., Nguyen, Q. T., \& Sauzéat, C. (2011). Nonlinearity, heating, fatigue and thixotropy during cyclic loading of asphalt mixtures. Road Materials and Pavement Design, 12(1), 129-158. https://doi.org/10.1080/14680629.2011.9690356

Hou, T., Underwood, B. S., \& Kim, Y. R. (2010). Fatigue performance prediction of North Carolina mixtures using the simplified viscoelastic continuum damage model. In Asphalt Paving Technology: Association of Asphalt Paving Technologists-Proceedings of the Technical Sessions.

Isailović, I., Wistuba, M. P., \& Cannone Falchetto, A. (2017). Influence of rest period on asphalt recovery considering nonlinearity and self-heating. Construction and Building Materials, 140, 321-327. https://doi.org/10.1016/j.conbuildmat.2017.02.122

Isailović, I., Wistuba, M. P., \& Falchetto, A. C. (2017). Experimental study on asphalt mixture recovery. Materials and Structures/Materiaux et Constructions. https://doi.org/10.1617/s11527-017-1064-0

Lundström, R., Ekblad, J., \& Isacsson, U. (2004). Influence of Hysteretic Heating on Asphalt Fatigue Characterization. Journal of Testing and Evaluation. https://doi.org/10.1520/jte12284

Mangiafico, S., Sauzéat, C., Di Benedetto, H., Pouget, S., Olard, F., \& Planque, L. (2015). Quantification of biasing effects during fatigue tests on asphalt mixes: Non-linearity, selfheating and thixotropy. Road Materials and Pavement Design, 16(Supplement 2), 143180. https://doi.org/10.1080/14680629.2015.1077000 
Mangiafico, Salvatore, Di Benedetto, H., Sauzéat, C., Olard, F., Pouget, S., \& Planque, L. (2016). Effect of colloidal structure of bituminous binder blends on linear viscoelastic behaviour of mixtures containing Reclaimed Asphalt Pavement. Materials and Design, 111, 126139. https://doi.org/10.1016/j.matdes.2016.07.124

Mensching, D. J., Rahbar-Rastegar, R., Underwood, B. S., \& Daniel, J. S. (2016). Identifying indicators for fatigue cracking in hot-mix asphalt pavements using viscoelastic continuum damage principles. Transportation Research Record. https://doi.org/10.3141/2576-04

Nguyen, Q. T., Di Benedetto, H., \& Sauzéat, C. (2014). Linear Viscoelastic domain for Bituminous Mixtures. In Pavement Materials, Structures, and Performance GSP 239 (pp. 59-68). Shangai, China: ASCE.

Olard, F., \& Di Benedetto, H. (2003). General "2S2P1D" Model and Relation Between the Linear Viscoelastic Behaviours of Bituminous Binders and Mixes. Road Materials and Pavement Design. https://doi.org/10.1080/14680629.2003.9689946

Olard, F., Di Benedetto, H., Eckmann, B., \& Triquigneaux, J. P. (2003). Linear Viscoelastic Properties of Bituminous Binders and Mixtures at Low and Intermediate Temperatures. Road Materials and Pavement Design. https://doi.org/10.1080/14680629.2003.9689941

Pérez-Jiménez, F., Botella, R., \& Miró, R. (2012). Damage and Thixotropy in Asphalt Mixture and Binder Fatigue Tests. Transportation Research Record: Journal of the Transportation Research Board. https://doi.org/10.3141/2293-02

Pérez-Jiménez, F. E., Botella, R., \& Miró, R. (2012). Differentiating between damage and thixotropy in asphalt binder's fatigue tests. Construction and Building Materials, 31, 212219. https://doi.org/10.1016/j.conbuildmat.2011.12.098

Pérez-Jiménez, F., Valdés, G., Miró, R., Botella, R., \& Campana, J. M. (2011). Effect of Thermal Stresses on Fatigue Behavior in Bituminous Mixes. Transportation Research Record: Journal of the Transportation Research Board. https://doi.org/10.3141/2210-10

Pérez-Jiménez, Félix E., Botella, R., Miró, R., \& Martínez, A. H. (2015). Analysis of the thixotropic behavior and the deterioration process of bitumen in fatigue tests. Construction and Building Materials, 101, 277-286. https://doi.org/10.1016/j.conbuildmat.2015.10.113

Reese, R. (1997). Properties of Aged Binder Related to Asphalt Concrete Fatigue Life. Journal of Association of Asphalt Paving Technologists, 66, 604-632.

Riahi, E., Allou, F., Botella, R., Dubois, F., Absi, J., \& Petit, C. (2017). Quantification of selfheating and its effects under cyclic tests on a bituminous binder. International Journal of Fatigue, 104, 334-341. https://doi.org/10.1016/j.ijfatigue.2017.07.016

Riahi, E., Allou, F., Botella, R., Fakhari Tehrani, F., Dubois, F., Absi, J., ... Pérez-Jiménez, F. E. (2017). Modelling self-heating and thixotropy phenomena under the cyclic loading of asphalt. Road Materials and Pavement Design, 18(sup2), 155-163. https://doi.org/10.1080/14680629.2017.1305145

Shan, L., Tan, Y., Underwood, B. S., \& Kim, Y. R. (2011). Separation of Thixotropy from Fatigue Process of Asphalt Binder. Transportation Research Record: Journal of the Transportation Research Board, 2207(1), 89-98. https://doi.org/10.3141/2207-12

Williams, M. L., Landel, R. F., \& Ferry, J. D. (1955). The Temperature Dependence of Relaxation Mechanisms in Amorphous Polymers and Other Glass-forming Liquids. Journal of the American Chemical Society. https://doi.org/10.1021/ja01619a008 
Zhang, J., Sabouri, M., Guddati, M. N., \& Kim, Y. R. (2013). Development of a failure criterion for asphalt mixtures under fatigue loading. Road Materials and Pavement Design.

https://doi.org/10.1080/14680629.2013.812843 